\title{
On the Periodicity of $\langle 001\rangle$ Symmetrical Tilt Grain Boundaries
}

\author{
Kazutoshi Inoue $^{1, *}$, Mitsuhiro Saito ${ }^{1,2}$, Zhongchang Wang ${ }^{1}$, \\ Motoko Kotani $^{1}$ and Yuichi Ikuhara ${ }^{1,2}$ \\ ${ }^{1}$ WPI Research Center, Advanced Institute for Materials Research, Tohoku University, Sendai 980-8577, Japan \\ ${ }^{2}$ Institute of Engineering Innovation, School of Engineering, The University of Tokyo, Tokyo 113-8656, Japan
}

We report an application of the O-lattice theory to systematically analyse the structures of symmetrical tilt grain boundaries with the rotation axis of $\langle 001\rangle$ and demonstrate a theoretical interpretation of the experimentally observed structures of a near $\Sigma 5$ grain boundary in $\mathrm{MgO}$ in terms of the structural-units model and the periodicity of the O-points on the boundary. We further derive generalised decomposition formulae for the symmetrical tilt grain boundaries which are closely related to the distribution of irreducible rational numbers.

[doi:10.2320/matertrans.M2014394]

(Received November 7, 2014; Accepted December 16, 2014; Published February 6, 2015)

Keywords: atomic structure, crystal structure, dislocations, symmetrical tilt grain boundary, structural unit, O-lattice

\section{Introduction}

Grain boundaries with a large index rarely exist in nature, and can be decomposed into the ones with a smaller index due to relaxation. Over two decades ago, both symmetrical and asymmetrical tilt grain boundaries were intensively studied $^{1-16)}$ and a general consensus was that actual configurations of grain boundaries could be realised by arranging smaller structural units. Since then, numerous experiments and calculations on the grain boundary geometries have been conducted and the study of interfaces in crystalline materials was summarised by A. P. Sutton and R. W. Balluffi. ${ }^{17)}$ R. C. Pond and his collaborators provided a general theoretical framework in regard to the symmetry of space groups and point groups on the dichromatic pattern and complex of two adjacent lattices ${ }^{18,19}$ that was closely related to the periodic appearance of structural units as energetically stable configurations.

Recently, observations due to high resolutional microscopy combined with theoretical calculations have been conducted $^{20-23)}$ and M. Saito et al. $^{24)}$ observed the atomic-scale structures of symmetrical tilt grain boundaries with a bonding angle of $35.3^{\circ}$ in a bicrystal of $\mathrm{MgO}$. They demonstrated that the (410)-structural units of $\Sigma 17$ are periodically intercalated in between the (310)-structural units of $\Sigma 5$ and recognised such phenomenon as the periodic appearance of displacement-shift-complete (DSC) dislocations.

While most of the successful works relied on microscopical observations and extensive numerical calculations, we propose a novel method to analyse the structures of symmetrical tilt grain boundaries of simple cubic crystals with the rotation axis of $\langle 001\rangle$ with a mathematically evident argument. Sutton et al. gave an algorithm to obtain the arrangement of structural units assuming that the boundary structure can be described by two favoured boundaries as a linear combination of them with coprime integral coefficients and the structure changes as continuously as possible according to the misorientation. ${ }^{3)}$ Our approach to describe the boundary structure is the converse of their argument. We directly derive the decomposition formula of the $\langle 001\rangle$ grain

*Corresponding author, E-mail: kinoue@wpi-aimr.tohoku.ac.jp boundaries and reproduce the previously observed results by the aid of the structural-units model and conventionallycalled the O-lattice theory. The ratio of the number of the structural units is precisely given as a corollary.

The O-lattice theory was introduced by W. Bollmann ${ }^{25-29)}$ as a way of generalisations of the coincidence-site-lattice (CSL) theory. ${ }^{30}$ We utilise the O-lattice as an indicator of the periodicity of the structural units and therefore, it is different from the way Bollmann proposed. In this theory, let $L_{0}$ be a 2-dimensional square lattice and $L_{1}, L_{2}$ be lattices which satisfy $L_{i}=A_{i}\left(L_{0}\right)(i=1,2)$ for a non-degenerate linear transformation $A_{i}$. Let $U\left(L_{0}\right)$ denote the unit cell of $L_{0}$ and $\left|U\left(L_{0}\right)\right|$ denote its area. In what follows, the pair of lattices $\left(L_{0}, L_{1}\right)$ is assumed to be a configuration slightly deviated from the optimal configuration $\left(L_{0}, L_{2}\right)$. For the dichromatic pattern $^{18,19)}$ of a pair of lattices $\left(L_{0}, L_{i}\right)$, an O-point $\boldsymbol{a}$ with respect to $A_{i}$ can be expressed by the following basic equation which can be derived by the Frank-Bilby formula: ${ }^{31-34)}$

$$
\left(I-A_{i}^{-1}\right) \boldsymbol{a}=\boldsymbol{t}_{\mathbf{0}},
$$

where $I$ is the identity matrix and $\boldsymbol{t}_{\mathbf{0}}$ is an arbitrary translational vector in $L_{0}$. From the eq. (1), $\boldsymbol{a}$ is recognized as the centre of the linear transformation $A_{i}$ in the dichromatic pattern of $\left(L_{0}, L_{i}\right)$. In this sense, the O-lattice is a way of generalisation of the CSL since any of the CSL points can be the centre of a rotational transformation. One of the points the O-lattice theory has been criticised is that the choice of $A_{i}$ is not unique. However, this ambiguity allows us to choose an appropriate transformation according to the problem. Let $\mathcal{O}_{A_{i}}\left(L_{0}, L_{i}\right)$ denote the O-lattice of $\left(L_{0}, L_{i}\right)$ with respect to $A_{i}$. Conversely, given an O-point and the transformation $A_{i}$, the configuration of the lattices around it is recovered. From the eq. (1), one can see that $\left|U\left(L_{0}\right)\right| /\left|\operatorname{det}\left(I-A_{i}^{-1}\right)\right|$ gives the area of the unit cell of the O-lattice and therefore that $\left|\operatorname{det}\left(I-A_{i}^{-1}\right)\right|$ is a sort of the density of O-points as with $\Sigma$ in the CSL theory. Generally, an O-lattice is a super-lattice of the CSL in a CSL configuration if $A_{i}$ is a rotational transformation and thus the unit cell of an O-lattice is smaller than that of the CSL. The O-points can be classified in terms of the internal coordinates. Two O-points are equivalent if their internal coordinates coincide, the representatives of which are called the reduced O-points. It can be shown that 
Table 1 Examples of reduced O-points for the small $\Sigma$ 's if $A_{i}$ is a rotational transformation.

\begin{tabular}{ccccc}
\hline$\Sigma$ & $2 \theta$ & $\cot \theta$ & g.b. plane & reduced O-points \\
\hline$\Sigma 13$ & $22.62^{\circ}$ & 5 & $(510)$ & $(0,0),(1 / 2,1 / 2)$ \\
$\Sigma 17$ & $28.07^{\circ}$ & 4 & $(410)$ & $(0,0),(1 / 2,1 / 2),(0,1 / 2),(1 / 2,0)$ \\
$\Sigma 5$ & $36.87^{\circ}$ & 3 & $(310)$ & $(0,0),(1 / 2,1 / 2)$ \\
$\Sigma 5$ & $53.13^{\circ}$ & 2 & $(210)$ & $(0,0),(1 / 2,1 / 2),(0,1 / 2),(1 / 2,0)$ \\
\hline
\end{tabular}

there are two types (resp. four types) of reduced O-points for the ( $\left.\begin{array}{lll}m & 1 & 0\end{array}\right)$-plane where $m$ is an odd (resp. even) integer if $A_{i}$ is a rotational transformation. Table 1 shows the examples of the reduced O-points for the small $\Sigma$ 's.

The O-lattice defined above is called the primary O-lattice or simply the $\mathrm{O}_{1}$-lattice. As an alternative, we can also define a secondary O-lattice or simply an $\mathrm{O}_{2}$-lattice. The $\mathrm{O}_{1}$-lattice $\mathcal{O}_{A_{i}}\left(L_{0}, L_{i}\right)$ can be defined for each $i=1,2$. Then the transformation $A_{1} A_{2}^{-1}$ maps $L_{2}$ to $L_{1}$ and thus the transformation $\left(I-A_{1}^{-1}\right)^{-1}\left(I-A_{2}^{-1}\right)$ maps $\mathcal{O}_{A_{2}}\left(L_{0}, L_{2}\right)$ to $\mathcal{O}_{A_{1}}\left(L_{0}, L_{1}\right)$. Letting $B=\left(I-A_{1}^{-1}\right)^{-1}\left(I-A_{2}^{-1}\right)$, the $\mathrm{O}_{2-}$ lattice is defined to be the $\mathrm{O}_{1}$-lattice of two $\mathrm{O}_{1}$-lattices with respect to the transformation $B$. Namely, an $\mathrm{O}_{2}$-point $\boldsymbol{b}$ is given by ${ }^{25}$ )

$$
\left(I-B^{-1}\right) b=t_{1},
$$

where $t_{1}$ is an arbitrary translational vector in the reference $\mathrm{O}_{1}$-lattice $\mathcal{O}_{A_{2}}\left(L_{0}, L_{2}\right)$. The basic equation of the $\mathrm{O}_{2}$-lattice is also given by

$$
\left(I-A_{1} A_{2}^{-1}\right) b=\boldsymbol{t}_{2},
$$

where $\boldsymbol{t}_{\mathbf{2}}$ is an arbitrary translational vector of the DSC lattice of $\left(L_{0}, L_{2}\right)$. The $\mathrm{O}_{2}$-lattice is in general a sub-lattice of the reference $\mathrm{O}_{1}$-lattice. It is expected that the secondary dislocations (or the DSC dislocations) are introduced into the boundary of the Wigner-Seitz cells of the $\mathrm{O}_{2}$-points under the assumptions that the deviation of $\left(L_{0}, L_{1}\right)$ from the optimal configuration $\left(L_{0}, L_{2}\right)$ is small enough. ${ }^{28,35,36)}$

\section{Application of the O-Lattice Theory}

We first demonstrate the application of the O-lattice theory by focusing on the symmetrical tilt CSL grain boundaries. The term near $C S L^{37)}$ can be defined as a configuration of a pair of two lattices which are, in a sense, close to an optimal configuration (a favoured boundary, ${ }^{3)}$ or a preferred state ${ }^{28)}$ ). Note that the term near CSL can be used even for a CSL configuration with a high $\Sigma$. Let $L_{i}$ be given by the rotation of $L_{0}$ with a rotational transformation $R\left(2 \theta_{i}\right)$ of the angle of $2 \theta_{i}$ $(i=1,2)$, respectively. It is assumed that a CSL configuration with a high $\Sigma$ can be approximated by two of the optimal reference configurations with low $\Sigma$ 's. In this way, the periodicity of grain boundaries can be easily evaluated by the structural-units model. ${ }^{2-5)}$ In this paper, we consider the ( $q p$ 0)-planes. As highlighted in Fig. 1, the structural unit of symmetrical ( $q p 0$ )-grain boundary can be defined to be a kite-shaped tetragon which is made by gluing a pair of right triangles of a group of atoms at their hypotenuses whose sides in the right angles are $q a$ and $p a$ where $a$ is the average atomic distance. Since a desired resolution around the

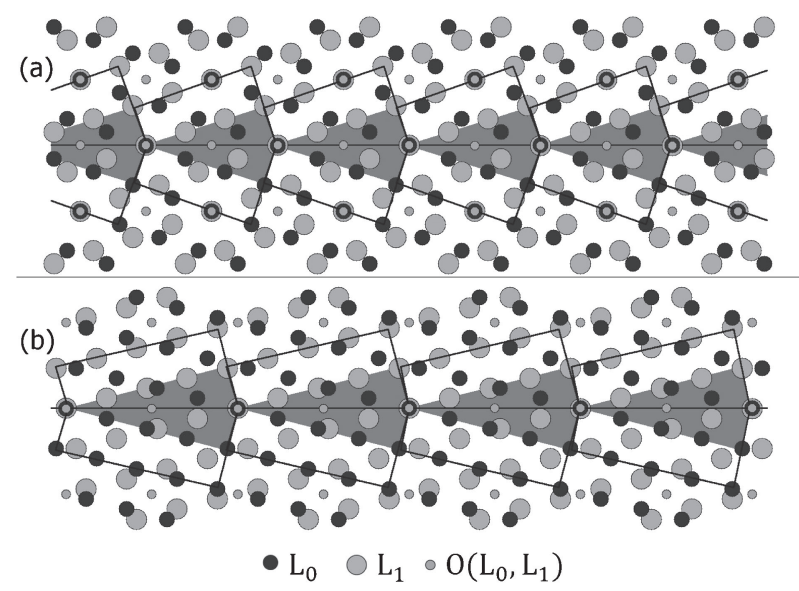

Fig. 1 (a) The (310)-structural units of the $\Sigma 5$ boundary and (b) the (410)structural units of the $\Sigma 17$ boundary. The reference lattice $L_{0}$, the rotated lattice $L_{1}$ and the O-lattice $\mathcal{O}\left(L_{0}, L_{1}\right)$ are presented.

boundary may not always be obtained, we take a larger cell enclosing the structural unit defined above. Figure 1 shows the atomic configurations of the (310)-structural units of the $\Sigma 5$ boundary and the (410)-structural units of the $\Sigma 17$ boundary where two lattices $L_{0}$ and $L_{1}$ are superposed. The CSL boundary is defined by the line passing through the CSL points below which there are points of $L_{0}$ and above which there are points of $L_{1}$.

If $\left(L_{0}, L_{1}\right)$ is of a CSL configuration, it holds that $\tan \theta_{1}=p / q$ for coprime positive integers $p$ and $q$. It is shown that the periodicity of the structural units in the ( $q$ p 0 )-plane is $p$. By taking $A=R\left(2 \theta_{1}\right)$ in the eq. (1), we have

$$
\left(I-R\left(2 \theta_{1}\right)^{-1}\right)^{-1}=\frac{1}{2}\left(\begin{array}{cc}
1 & q / p \\
-q / p & 1
\end{array}\right) .
$$

By applying the eq. (4) to a translational vector $(0, l)$ of $L_{0}$ for an integer $l$ to obtain the O-points on the ( $q p 0)$-plane, one can have

$$
\left(I-R\left(2 \theta_{1}\right)^{-1}\right)^{-1}\left(\begin{array}{l}
0 \\
l
\end{array}\right)=\frac{l}{2}\left(\begin{array}{c}
q / p \\
1
\end{array}\right) .
$$

Then the point $l / 2(q / p 10)$ belongs to the ( $q p 0)$-plane. The CSL points are obtained by the eq. (5) if the parameter $l$ is divisible by $2 p$. If $l$ is odd, the first component of the eq. (5) varies while the second component is maintained at $1 / 2$ in terms of the internal coordinates. It is concluded that the internal coordinates in the eq. (5) is periodic and the periodicity can be precisely given by $2 p$. By drawing virtual structural units passing through $\mathrm{O}_{1}$-points alternately, it can be shown that the periodicity of the structural units is given by $p$.

In order to validate the above method, we consider the (22 7 0)-structure as a model case which corresponds to the misorientation of the angle of $35.300^{\circ}\left(\tan \left(35.300^{\circ} / 2\right) \simeq\right.$ $7 / 22$ ) and is a near (310) $\Sigma 5$-structure of the angle of $36.869^{\circ}$ $\left(\tan \left(36.869^{\circ} / 2\right) \simeq 1 / 3\right)$. Figure 2 shows the dichromatic pattern of the (22 70 )-structure with the unit cells of $L_{0}$. It can be seen that O-points in the virtual structural unit shifts periodically in $U\left(L_{0}\right)$. In the fourth structural unit from the left, one finds an O-point at the edge of $U\left(L_{0}\right)$ whose internal 


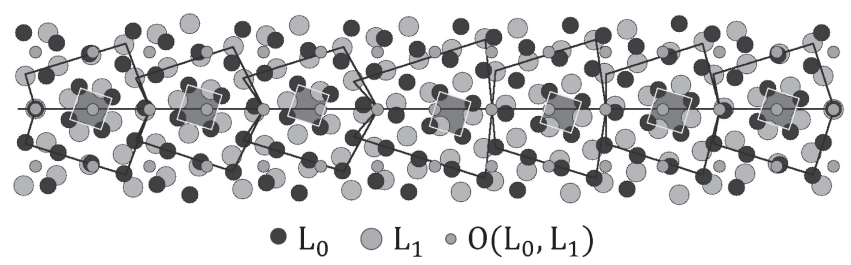

Fig. 2 The (22 7 0)-structure with virtual structural units. The reference lattice $L_{0}$, the rotated lattice $L_{2}$ of the angle of $35.30^{\circ}$ and the $O_{1}$-lattice $\mathcal{O}\left(L_{0}, L_{2}\right)$ are presented, indicating that $O_{1}$-point is shifted in the unit cell of $L_{0}$. After the relaxation, the virtual structural units are transformed to (possibly deformed) six (310)-units and one (410)-unit.

coordinates are $(0,1 / 2)$ with respect to the coordinate system of $L_{0}$. Since the theoretical grain boundary is on the (22 7 0)-plane the above argument suggests that the periodicity of the structural units is 7 . The deviation of the angle $35.300^{\circ}$ identifies this CSL configuration as $\Sigma 533$ which is in between $36.869^{\circ}(\Sigma 5)$ and $28.072^{\circ}(\Sigma 17)$. Therefore this grain boundary can be described by the combination of the (310) and the (410)-planes. The internal coordinates of the eq. (5) becomes $(0,1 / 2)$ if $l=7+14 k$ for each integer $k$ which appears not in the $\Sigma 5$ but in the $\Sigma 17$ configuration (Table 1). The decomposition is thus given by the linear combination with integral coefficients of the reference boundaries. ${ }^{3)}$ Namely, it holds that $\left(\begin{array}{lll}22 & 7 & 0\end{array}\right)=6\left(\begin{array}{lll}3 & 1 & 0\end{array}\right)+$ 1(4 10$)$, which is viewed as a decomposition of a reciprocal vector. Once two reference structures are determined appropriately, one can obtain the integral coefficients uniquely for a specific grain boundary. Figure 3 shows an ABF-STEM image of the $\mathrm{MgO}$ grain boundary with a bonding angle of $35.3^{\circ}$ and a corresponding schematic plot of the structural units, indicating that the periodicity of the structural units is 7 though it can be varied in the presence of impurities. $^{24)}$

For each $m=2,3,4,5, \ldots$, let $p / q$ be a rational number for coprime positive integers $p$ and $q$ with $1 / m<p / q<$ $1 /(m-1)$. Since the $\left(\begin{array}{lll}m & 1 & 0\end{array}\right)$ and the $\left(\begin{array}{lll}m-1 & 1 & 0\end{array}\right)$-planes can be the reference structures for the ( $q p 0)$-plane, the first decomposition rule is summarised as follows:

$$
(q p 0)=n_{1}\left(\begin{array}{lll}
m & 1 & 0
\end{array}\right)+n_{2}(m-110),
$$

where $n_{1}=q-(m-1) p$ and $n_{2}=-q+m p$ are positive integers. Similar equations were discussed by A. A. Levi et $a l .{ }^{15)}$ and by Sutton et al. ${ }^{38)}$ to describe the arrangement of the structural units. Note that $n_{1}+n_{2}=p$ defines the periodicity of the structural units. It holds that $n_{1}>n_{2}$ if the $(q p 0)$-plane is close to the (m 10$)$-plane i.e. $1 / m<$ $p / q<2 /(2 m-1)$ and $n_{1}<n_{2}$ holds otherwise where $2 /(2 m-1)$ is the harmonic average of $1 / m$ and $1 /(m-1)$. The eq. (6) not only agrees with the microscopical observation by Saito et al. ${ }^{24)}$ but successfully generalise the results of theoretical calculations by G. J. Wang et al., ${ }^{8,9)}$ relatively recent results by S. P. Chen et al., ${ }^{14)}$ and most of the experimental results by N. D. Browning et al. ${ }^{16)}$ It should be remarked that our argument goes in the opposite direction of Sutton's. ${ }^{3)}$ Although we only focus on the near $\left(\begin{array}{lll}3 & 1 & 0\end{array}\right) \Sigma 5$ grain boundaries in this paper, the formula can be valid in more general cases which will be discussed further. Readers can refer to the decomposition table of the ( $q p 0)$-planes

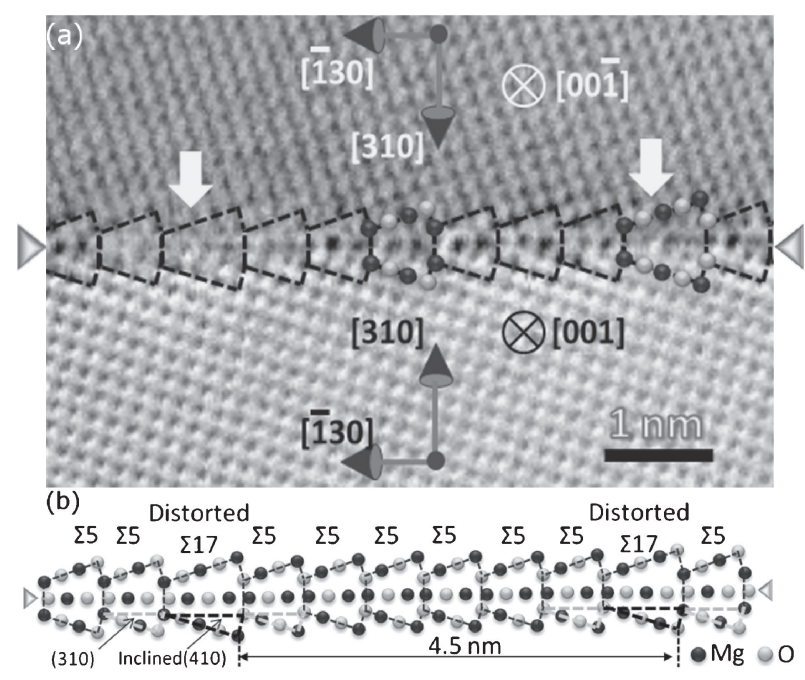

Fig. 3 An ABF-STEM image of the grain boundary in $\mathrm{MgO}$ with a bonding angle of $35.3^{\circ 24)}$ and the schematic plot of structural units.

around $\Sigma 5\left(2 \theta=36.869^{\circ}\right)$ with $p<10$ presented in Table 2 and more detailed cases for larger $p$ 's in the appendix.

We may assume that the periodicity $p$ is smaller than 10 since nature might not prefer a long periodicity. Then it can be shown that the numerators of the irreducible rational numbers in between $1 / m$ and $1 /(m-1)$ which are smaller than 10 form a mirror-symmetric sequence $\left\{p_{l}\right\}_{l=1}^{29}$ :

$$
\begin{array}{r}
1, \underline{\mathbf{9}}, 8,7,6,5, \underline{\mathbf{9}}, 4, \underline{\mathbf{7}}, 3, \underline{\mathbf{8}}, 5,7, \underline{\mathbf{9}}, 2, \\
\underline{\mathbf{9}}, 7,5, \underline{\mathbf{8}}, 3, \underline{\mathbf{7}}, 4, \underline{\mathbf{9}}, 5,6,7,8, \underline{\mathbf{9}}, 1 .
\end{array}
$$

For instance, irreducible rational numbers in between $1 / 4$ and $1 / 3$ whose numerators are less than 10 can be given by $1 / 4$, $9 / 35,8 / 31,7 / 27,6 / 23,5 / 19,9 / 34,4 / 15,7 / 26,3 / 11,8 / 29$, $5 / 18,7 / 25,9 / 32,2 / 7,9 / 31,7 / 24,5 / 17,8 / 27,3 / 10,7 / 23$, $4 / 13,9 / 29,5 / 16,6 / 19,7 / 22,8 / 25,9 / 28,1 / 3$. Therefore, if $p_{1}=1$ and $p_{29}=1$ correspond to the (410)-plane with $28.072^{\circ}$ and the (310)-plane with $36.869^{\circ}$, respectively, $p_{26}=7$ corresponds to the (22 70$)$-plane with $2 \theta=$ $35.300^{\circ}$. It is observed that $p_{l}=p_{l-1}+p_{l+1}$ holds for $l=2,7,9,11,14,16,19,21,23,28$ (underlined) corresponding to the decomposition of a periodicity $p_{l}$ to $p_{l-1}$ and $p_{l+1}$ which can be also shown by the periodicity of the O-points. Let $q_{l}$ be the denominator that corresponds to $p_{l}$. We can now propose the second decomposition rule as follows. If it satisfies that $p_{l}=p_{l-1}+p_{l+1}$, the eq. (6) can be modified to

$$
\begin{aligned}
& \left(\begin{array}{lll}
q_{l} & p_{l} & 0
\end{array}\right)=\left[n_{l-1}^{(1)}\left(\begin{array}{lll}
m & 1 & 0
\end{array}\right)+n_{l-1}^{(2)}\left(\begin{array}{lll}
m-1 & 1 & 0
\end{array}\right)\right] \\
& +\left[n_{l+1}^{(1)}\left(\begin{array}{lll}
m & 1 & 0
\end{array}\right)+n_{l+1}^{(2)}(m-1 \quad 1 \quad 0)\right],
\end{aligned}
$$

where $n_{l}^{(i)}=n_{l-1}^{(i)}+n_{l+1}^{(i)}(i=1,2)$ satisfying that $n_{L}^{(1)}=q_{L}-$ $(m-1) p_{L}$ and $n_{L}^{(2)}=-q_{L}+m p_{L}(L=l-1, l, l+1)$. For instance, the (32 90 )-structure corresponding to the misorientation angle of $31.417^{\circ}$ decomposes into $5(410)+$ 4(3 10 l $)$ according to the eq. (6). On the other hand, since $9 / 32$ is in between $7 / 25$ and $2 / 7$, the (32 90 )-structure can be composed of the (25 70 ) and the (7 20$)$-structures, each of which decomposes into 4(4 110$)+3\left(\begin{array}{lll}3 & 1 & 0\end{array}\right)$ and $\left(\begin{array}{lll}4 & 1 & 0\end{array}\right)+$ (3 10 ), respectively, corresponding to the decomposition of the periodicity 9 into 7 and 2 . It can be easily seen in Table 2 . Note that the ( $m$ 1 0$)$-plane can be decomposed into smaller indices when $m$ is greater than 4 . 


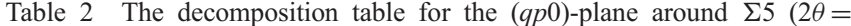
$\left.36.869^{\circ}\right)$ with $p<10$ is presented. The reference configurations are denoted by $\mathrm{A}=\left(\begin{array}{lll}4 & 1 & 0\end{array}\right), \mathrm{B}=\left(\begin{array}{lll}3 & 1 & 0\end{array}\right)$ and $\mathrm{C}=\left(\begin{array}{lll}2 & 1 & 0\end{array}\right)$ which are represented in boldstyle. The second rule of decomposition in the eq. (8) is observed.

\begin{tabular}{|c|c|c|c|c|}
\hline $2 \theta\left[^{\circ}\right]$ & $\tan \theta$ & $\Sigma$ & g.b. plane & decomposition \\
\hline 28.072 & $1 / 4$ & 17 & $\left(\begin{array}{lll}4 & 1 & 0\end{array}\right)$ & $\mathbf{A}$ \\
\hline 28.841 & $9 / 35$ & 653 & $\left(\begin{array}{lll}35 & 9 & 0\end{array}\right)$ & $8 \mathrm{~A}+1 \mathrm{~B}$ \\
\hline 28.940 & $8 / 31$ & 1025 & 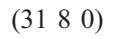 & $7 \mathrm{~A}+1 \mathrm{~B}$ \\
\hline 29.068 & $7 / 27$ & 389 & $\left(\begin{array}{lll}27 & 7 & 0\end{array}\right)$ & $6 \mathrm{~A}+1 \mathrm{~B}$ \\
\hline 29.241 & $6 / 23$ & 565 & $\left(\begin{array}{lll}23 & 6 & 0\end{array}\right)$ & $5 \mathrm{~A}+1 \mathrm{~B}$ \\
\hline 29.487 & $5 / 19$ & 193 & $(1950)$ & $4 \mathrm{~A}+1 \mathrm{~B}$ \\
\hline 29.652 & $9 / 34$ & 1237 & $\left(\begin{array}{lll}34 & 9 & 0\end{array}\right)$ & $7 \mathrm{~A}+2 \mathrm{~B}$ \\
\hline 29.862 & $4 / 15$ & 241 & $\left(\begin{array}{lll}15 & 4 & 0\end{array}\right)$ & $3 \mathrm{~A}+1 \mathrm{~B}$ \\
\hline 30.136 & $7 / 26$ & 725 & 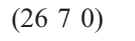 & $5 \mathrm{~A}+2 \mathrm{~B}$ \\
\hline 30.510 & $3 / 11$ & 65 & $\left(\begin{array}{lll}1 & 3 & 0\end{array}\right)$ & $2 \mathrm{~A}+1 \mathrm{~B}$ \\
\hline 30.844 & $8 / 29$ & 905 & $\left(\begin{array}{lll}2 & 9 & 8\end{array}\right)$ & $5 \mathrm{~A}+3 \mathrm{~B}$ \\
\hline 31.048 & $5 / 18$ & 349 & $\left(\begin{array}{lll}18 & 5 & 0\end{array}\right)$ & $3 \mathrm{~A}+2 \mathrm{~B}$ \\
\hline 31.284 & $7 / 25$ & 337 & $\left(\begin{array}{llll}2 & 5 & 7 & 0\end{array}\right)$ & $4 A+3 B$ \\
\hline 31.417 & $9 / 32$ & 1105 & $\left(\begin{array}{lll}32 & 9 & 0\end{array}\right)$ & $5 \mathrm{~A}+4 \mathrm{~B}$ \\
\hline 31.890 & $2 / 7$ & 53 & $\left(\begin{array}{lll}7 & 2 & 0\end{array}\right)$ & $1 \mathrm{~A}+1 \mathrm{~B}$ \\
\hline 32.378 & $9 / 31$ & 521 & 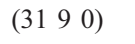 & $4 A+5 B$ \\
\hline 32.520 & $7 / 24$ & 625 & 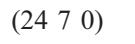 & $3 A+4 B$ \\
\hline 32.779 & $5 / 17$ & 157 & $\left(\begin{array}{lll}17 & 5 & 0\end{array}\right)$ & $2 \mathrm{~A}+3 \mathrm{~B}$ \\
\hline 33.008 & $8 / 27$ & 793 & 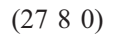 & $3 \mathrm{~A}+5 \mathrm{~B}$ \\
\hline 33.398 & $3 / 10$ & 109 & $\left(\begin{array}{lll}10 & 3 & 0\end{array}\right)$ & $1 \mathrm{~A}+2 \mathrm{~B}$ \\
\hline 33.855 & $7 / 23$ & 289 & 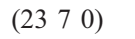 & $2 \mathrm{~A}+5 \mathrm{~B}$ \\
\hline 34.205 & $4 / 13$ & 185 & 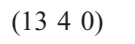 & $1 \mathrm{~A}+3 \mathrm{~B}$ \\
\hline 34.482 & $9 / 29$ & 461 & 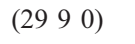 & $2 \mathrm{~A}+7 \mathrm{~B}$ \\
\hline 34.708 & $5 / 16$ & 281 & $\left(\begin{array}{lll}16 & 5 & 0\end{array}\right)$ & $1 \mathrm{~A}+4 \mathrm{~B}$ \\
\hline 35.051 & $6 / 19$ & 397 & $\left(\begin{array}{lll}19 & 6 & 0\end{array}\right)$ & $1 \mathrm{~A}+5 \mathrm{~B}$ \\
\hline 35.300 & $7 / 22$ & 533 & 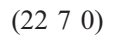 & $1 A+6 B$ \\
\hline 35.489 & $8 / 25$ & 689 & $\left(\begin{array}{lll}2 & 8 & 0\end{array}\right)$ & $1 \mathrm{~A}+7 \mathrm{~B}$ \\
\hline 35.637 & $9 / 28$ & 865 & $\left(\begin{array}{lll}28 & 9 & 0\end{array}\right)$ & $1 \mathrm{~A}+8 \mathrm{~B}$ \\
\hline 36.869 & $1 / 3$ & 5 & $\left(\begin{array}{lll}3 & 1 & 0\end{array}\right)$ & B \\
\hline
\end{tabular}

Continued on next column.

The findings by Saito et al. ${ }^{24)}$ can be interpreted from a viewpoint of the $\mathrm{O}_{2}$-lattice. Figure 4 shows the dichromatic pattern of the (22 70 )-structure with the virtual structural units in which the line passing through the CSL points indicates the (22 7 0)-boundary connecting two CSL $\mathrm{O}_{2}$ points and the diagonal lines are the boundary of the WignerSeitz cells of $\mathrm{O}_{2}$-points. Given $\cot \theta_{2}$ is an odd integer, $A_{1}=R\left(2 \theta_{1}\right)$ and $A_{2}=R\left(2 \theta_{2}\right)$ in the eqs. (1) and (3), the area of the unit cells of the $\mathrm{O}_{1}$-lattice of $\left(L_{0}, L_{2}\right)$ and the $\mathrm{O}_{2}$ lattice of $\left(L_{0}, L_{1}, L_{2}\right)$ can be given by $V_{\mathrm{O}_{1}}=1 / 4 \sin ^{2} \theta_{2}$, $V_{\mathrm{O}_{2}}=\sin ^{2} \theta_{1} / 2 \sin ^{2} \Delta \theta$, respectively, where $\Delta \theta=\theta_{2}-\theta_{1}$. Since their unit cells are square, the ratio of the length of the side $l_{\mathrm{O}_{1}}$ and $l_{\mathrm{O}_{2}}$ can be given by

$$
\frac{l_{\mathrm{O}_{2}}}{l_{\mathrm{O}_{1}}}=\frac{\sqrt{2}}{\left|\cot \theta_{1}-\cot \theta_{2}\right|} .
$$

By taking $\cot \theta_{1}=22 / 7\left(2 \theta_{1}=35.30^{\circ}\right)$ and $\cot \theta_{2}=$ $3\left(2 \theta_{2}=36.87^{\circ}\right)$, the value of the eq. (9) is given by $7 \sqrt{2}$. The length of the diagonal line of the unit $\mathrm{O}_{2}$-cell is therefore estimated to be $14 l_{\mathrm{O}_{1}}$, indicating that there are $15 \mathrm{O}_{1}$-points that are arrayed regularly on the CSL boundary in Fig. 4. The theory of the $\mathrm{O}_{2}$-lattice suggests that a DSC dislocation can
Continued

\begin{tabular}{|c|c|c|c|c|}
\hline $2 \theta\left[^{\circ}\right]$ & $\tan \theta$ & $\Sigma$ & g.b. plane & decomposition \\
\hline 36.869 & $1 / 3$ & 5 & $\left(\begin{array}{lll}3 & 1 & 0\end{array}\right)$ & B \\
\hline 38.186 & $9 / 26$ & 757 & 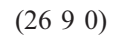 & $8 B+1 C$ \\
\hline 38.358 & $8 / 23$ & 593 & $\left(\begin{array}{lll}23 & 8 & 0\end{array}\right)$ & $7 B+1 C$ \\
\hline 38.580 & $7 / 20$ & 449 & (20 7 0 ) & $6 \mathrm{~B}+1 \mathrm{C}$ \\
\hline 38.880 & $6 / 17$ & 325 & $\left(\begin{array}{lll}17 & 6 & 0\end{array}\right)$ & $5 B+1 C$ \\
\hline 39.307 & $5 / 14$ & 221 & $\left(\begin{array}{lll}14 & 5 & 0\end{array}\right)$ & $4 B+1 C$ \\
\hline 39.597 & $9 / 25$ & 353 & $\left(\begin{array}{lll}25 & 9 & 0\end{array}\right)$ & $7 B+2 C$ \\
\hline 39.966 & $4 / 11$ & 137 & $\left(\begin{array}{lll}1 & 4 & 0\end{array}\right)$ & $3 B+1 C$ \\
\hline 40.449 & $7 / 19$ & 205 & (19 7 0) & $5 B+2 C$ \\
\hline 41.112 & $3 / 8$ & 73 & $\left(\begin{array}{lll}8 & 3 & 0\end{array}\right)$ & $2 B+1 C$ \\
\hline 41.708 & $8 / 21$ & 505 & $\left(\begin{array}{lll}2 & 8 & 0\end{array}\right)$ & $5 B+3 C$ \\
\hline 42.075 & $5 / 13$ & 97 & $\left(\begin{array}{lll}13 & 5 & 0\end{array}\right)$ & $3 B+2 C$ \\
\hline 42.501 & $7 / 18$ & 373 & $\left(\begin{array}{lll}18 & 7 & 0\end{array}\right)$ & $4 B+3 C$ \\
\hline 42.741 & $9 / 23$ & 305 & $\left(\begin{array}{lll}23 & 9 & 0\end{array}\right)$ & $5 B+4 C$ \\
\hline 43.602 & $2 / 5$ & 29 & $\left(\begin{array}{lll}5 & 2 & 0\end{array}\right)$ & $1 \mathrm{~B}+1 \mathrm{C}$ \\
\hline 44.498 & $9 / 22$ & 565 & $\left(\begin{array}{lll}2 & 9 & 9\end{array}\right)$ & $4 B+5 C$ \\
\hline 44.760 & $7 / 17$ & 169 & (17 7 0 $)$ & $3 B+4 C$ \\
\hline 45.239 & $5 / 12$ & 169 & $\left(\begin{array}{lll}12 & 5 & 0\end{array}\right)$ & $2 B+3 C$ \\
\hline 45.667 & $8 / 19$ & 425 & $\left(\begin{array}{lll}19 & 8 & 0\end{array}\right)$ & $3 B+5 C$ \\
\hline 46.397 & $3 / 7$ & 29 & $\left(\begin{array}{lll}7 & 3 & 0\end{array}\right)$ & $1 B+2 C$ \\
\hline 47.258 & $7 / 16$ & 305 & $\left(\begin{array}{lll}16 & 7 & 0\end{array}\right)$ & $2 B+5 C$ \\
\hline 47.924 & $4 / 9$ & 97 & $\left(\begin{array}{lll}9 & 4 & 0\end{array}\right)$ & $1 B+3 C$ \\
\hline 48.455 & $9 / 20$ & 481 & (20 99 ) & $2 B+7 C$ \\
\hline 48.887 & $5 / 11$ & 73 & $\left(\begin{array}{lll}11 & 5 & 0\end{array}\right)$ & $1 B+4 C$ \\
\hline 49.550 & $6 / 13$ & 205 & $\left(\begin{array}{lll}13 & 6 & 0\end{array}\right)$ & $1 B+5 C$ \\
\hline 50.033 & $7 / 15$ & 137 & $\left(\begin{array}{lll}15 & 7 & 0\end{array}\right)$ & $1 B+6 C$ \\
\hline 50.402 & $8 / 17$ & 353 & $\left(\begin{array}{lll}17 & 8 & 0\end{array}\right)$ & $1 B+7 C$ \\
\hline 50.692 & $9 / 19$ & 221 & (19 99 ) & $1 B+8 C$ \\
\hline 53.130 & $1 / 2$ & 5 & $\left(\begin{array}{lll}2 & 1 & 0\end{array}\right)$ & C \\
\hline
\end{tabular}

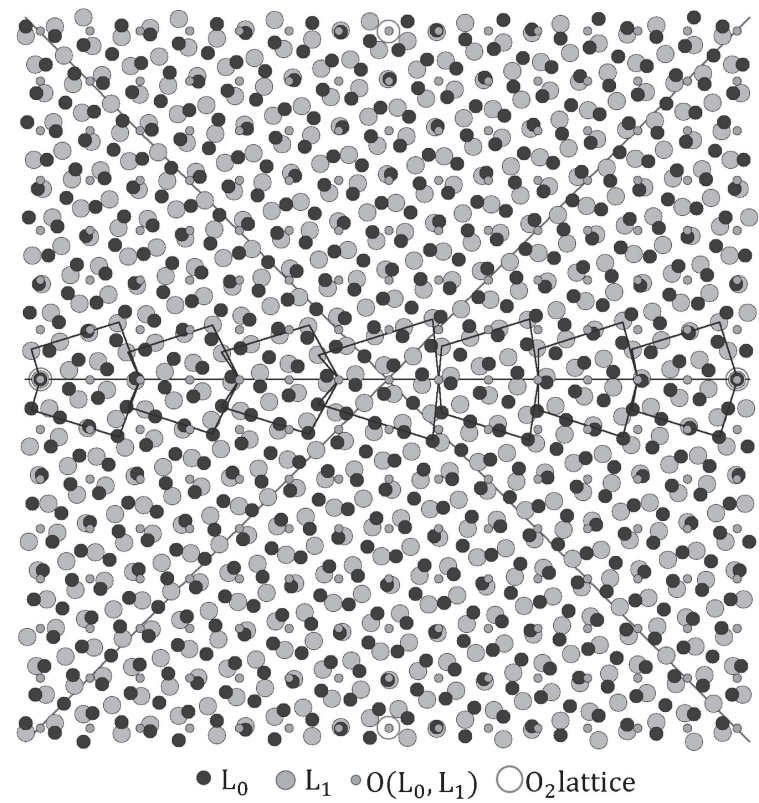

Fig. 4 The dichromatic pattern of the $(2270)$-structure with virtual structural units. The reference lattice $L_{0}$, the rotated lattice $L_{1}$ of angle of $35.30^{\circ}$, the $\mathrm{O}_{1}$-lattice $\mathcal{O}\left(L_{0}, L_{1}\right)$ and the $\mathrm{O}_{2}$-lattice are presented. The diagonal lines crossing perpendicularly shows the boundary of the Wigner-Seitz cells of $\mathrm{O}_{2}$-points. In the fourth structural unit from the left, a DSC dislocation can be introduced. 
be introduced at the intersection of the CSL boundary and the boundary of the Wigner-Seitz cells of the $\mathrm{O}_{2}$-lattice. It occurs at the middle of the array of $15 \mathrm{O}_{1}$-points where the internal coordinates of it are $(0,1 / 2)$. One of the atoms around the point should be shifted by the DSC Burgers vector close to [3 110$] / 10$ of the $\Sigma 5$ configuration through relaxation in order to localise the misfit.

\section{Conclusion}

We have applied the O-lattice theory to analyse the structures of symmetrical tilt grain boundaries of cubic crystals with the rotation axis $\langle 001\rangle$ and successfully derived a decomposition formula for symmetrical tilt near $\Sigma 5$ grain boundaries. We provide a convincing theoretical interpretation for the observed structures of a near $\Sigma 5$ grain boundary in $\mathrm{MgO}$ both from the structural-units model and the theory of the secondary O-lattice. The established theoretical formulae help to elucidate the fundamental structural relationship in a grain boundary and provide an approach for understanding structures of random grain boundaries.

\section{Acknowledgements}

The authors are grateful to Prof. Hideo Yoshinaga and Prof. Wenzheng Zhang for valuable discussions. This work is supported in part by Nippon Steel \& Sumitomo Metal Corporation, the Elements Strategy Initiative for Structural Materials (ESISM) by the MEXT of Japan, the JSPS Grantin-Aid for Scientific Research on Innovative Areas "Nano Informatics" (Grant No. 251006005), the Grant-in-Aid for Young Scientists (A) (grant no. 24686069), NSFC (grant no. 11332013) and, JSPS and CAS under the Japan-China Scientific Cooperation Program.

\section{REFERENCES}

1) G. H. Bishop and B. Chalmers: Scr. Metall. 2 (1968) 133-139.

2) A. P. Sutton and V. Vitek: Acta Metall. 14 (1980) 129-132.

3) A. P. Sutton and V. Vitek: Philos. Trans. R. Soc. Lond. A 309 (1983) $1-36$.

4) A. P. Sutton and V. Vitek: Philos. Trans. R. Soc. Lond. A 309 (1983) 37-54.

5) A. P. Sutton and V. Vitek: Philos. Trans. R. Soc. Lond. A 309 (1983) 55-68.

6) R. C. Pond, D. A. Smith and V. Vitek: Acta Metall. 27 (1979) 235-241.

7) R. W. Balluffi and P. D. Bristowe: Surf. Sci. 144 (1984) 28-43.

8) G.-J. Wang, A. P. Sutton and V. Vitek: Acta Metall. 32 (1984) 10931104.

9) G.-J. Wang and V. Vitek: Acta Metall. 34 (1986) 951-960.

10) R. C. Pond: Proc. R. Soc. A 357 (1977) 471-483.

11) R. C. Pond and V. Vitek: Proc. R. Soc. A 357 (1977) 453-470.

12) V. Vitek, D. A. Smith and R. C. Pond: Philos. Mag. 41 (1980) 649-663.

13) M. Kohyama: Phys. Stat. Sol. (b) 141 (1987) 71-83.

14) S. P. Chen, D. J. Srolovitz and A. F. Voter: J. Mat. Res. 4 (1989) 62-77.

15) A. A. Levi, D. A. Smith and J. T. Wetzel: J. Appl. Phys. 69 (1991) 2048-2056.

16) N. D. Browning, S. J. Pennycook, M. F. Chisholm, M. M. McGibbon and A. J. McGibbon: Interface Sci. 2 (1995) 397-423.

17) A. P. Sutton and R. W. Balluffi: Interfaces in Crystalline Materials, (Clarendon Press, Oxford, 1995).

18) R. C. Pond and W. Bollmann: Philos. Trans. R. Soc. Lond. A 292 (1979) 449-472.

19) R. C. Pond and D. S. Vlachavas: Proc. R. Soc. A 386 (1983) 95-143.
20) C. Schmidt, M. W. Finnis, F. Ernst and V. Vitek: Philos. Mag. A 77 (1998) 1161-1184.

21) N. Shibata, F. Oba, T. Yamamoto and Y. Ikuhara: Philos. Mag. 84 (2004) 2381-2415.

22) M. Imaeda, T. Mizoguchi, Y. Sato, H.-S. Lee, S. D. Findlay, N. Shibata, T. Yamamoto and Y. Ikuhara: Phys. Rev. B 78 (2008) 245320.

23) H. Hojo, T. Mizoguchi, H. Ohta, S. D. Findlay, N. Shibata, T. Yamamoto and Y. Ikuhara: Nano Lett. 10 (2010) 4668-4672.

24) M. Saito, Z. Wang, S. Tsukimoto and Y. Ikuhara: J. Mater. Sci. 48 (2013) 5470-5474.

25) W. Bollmann: Crystal Defects and Crystalline Interfaces, (SpringerVerlag, Berlin, 1970).

26) W. Bollmann: Surf. Sci. 31 (1972) 1-11.

27) R. C. Pond and D. A. Smith: Int. Met. Rev. June (1976) 61-74.

28) W. Bollmann: Crystal Lattices, Interfaces, Matrices, published by the author, Geneva, (1982).

29) C. Solenthaler and W. Bollmann: Mater. Sci. Eng. 81 (1986) 35-49.

30) S. Ranganathan: Acta Cryst. 21 (1966) 197-199.

31) F. C. Frank: Symposium on the Plastic Deformation of Crystalline Solids, (1950) pp. 150-154.

32) B. A. Bilby: Report on the Conference on Defects in Crystalline Solids, (1955) pp. 124-133.

33) J. W. Christian: The Theory of Transformations in Metals and Alloys, 3rd ed., (Pergamon, Oxford, 2002).

34) J. P. Hirth, R. C. Pond, R. G. Hoagland, X.-Y. Liu and J. Wang: Prog. Mat. Sci. 58 (2013) 749-823.

35) Z.-Z. Shi, F.-Z. Dai, M. Zhang, X.-F. Gu and W.-Z. Zhang: Metall. Mat. Trans. A 44 (2013) 2478-2486.

36) W.-Z. Zhang: Metall. Mat. Trans. A 44 (2013) 4513-4531.

37) G. A. Bruggeman, G. H. Bishop and W. H. Hartt: The Nature and Behavior of Grain Boundaries, (Plenum Press, New York, 1972) pp. 83-122.

38) A. P. Sutton: Prog. Mat. Sci. 36 (1992) 167-202.

\section{Appendix}

Table A.1 The decomposition table for the ( $q p$ 0)-plane around $\Sigma 5$ $\left(2 \theta=36.869^{\circ}\right)$ with $p<20$ is presented. The reference configurations are denoted by $\mathrm{A}=\left(\begin{array}{lll}4 & 1 & 0\end{array}\right), \mathrm{B}=\left(\begin{array}{lll}3 & 1 & 0\end{array}\right)$ and $\mathrm{C}=\left(\begin{array}{lll}2 & 1 & 0\end{array}\right)$ which are represented in boldstyle.

\begin{tabular}{|c|c|c|c|c|}
\hline $2 \theta\left[^{\circ}\right]$ & $\tan \theta$ & $\Sigma$ & g.b. plane & decomposition \\
\hline 28.072 & $1 / 4$ & 17 & $\left(\begin{array}{lll}4 & 1 & 0\end{array}\right)$ & $\mathbf{A}$ \\
\hline 28.431 & $19 / 75$ & 2993 & $\left(\begin{array}{lll}75 & 19 & 0\end{array}\right)$ & $18 \mathrm{~A}+1 \mathrm{~B}$ \\
\hline 28.451 & $18 / 71$ & 5365 & $\left(\begin{array}{lll}71 & 18 & 0\end{array}\right)$ & $17 \mathrm{~A}+1 \mathrm{~B}$ \\
\hline 28.474 & $17 / 67$ & 2389 & $\left(\begin{array}{lll}67 & 17 & 0\end{array}\right)$ & $16 \mathrm{~A}+1 \mathrm{~B}$ \\
\hline 28.500 & $16 / 63$ & 4225 & $\left(\begin{array}{lll}63 & 16 & 0\end{array}\right)$ & $15 \mathrm{~A}+1 \mathrm{~B}$ \\
\hline 28.529 & $15 / 59$ & 1853 & $\left(\begin{array}{lll}59 & 15 & 0\end{array}\right)$ & $14 \mathrm{~A}+1 \mathrm{~B}$ \\
\hline 28.562 & $14 / 55$ & 3221 & $\left(\begin{array}{lll}55 & 14 & 0\end{array}\right)$ & $13 \mathrm{~A}+1 \mathrm{~B}$ \\
\hline 28.600 & $13 / 51$ & 1385 & $\left(\begin{array}{lll}51 & 13 & 0\end{array}\right)$ & $12 \mathrm{~A}+1 \mathrm{~B}$ \\
\hline 28.645 & $12 / 47$ & 2353 & $\left(\begin{array}{lll}47 & 12 & 0\end{array}\right)$ & $11 \mathrm{~A}+1 \mathrm{~B}$ \\
\hline 28.698 & $11 / 43$ & 985 & $\left(\begin{array}{lll}43 & 11 & 0\end{array}\right)$ & $10 \mathrm{~A}+1 \mathrm{~B}$ \\
\hline 28.762 & $10 / 39$ & 1621 & $\left(\begin{array}{lll}39 & 10 & 0\end{array}\right)$ & $9 \mathrm{~A}+1 \mathrm{~B}$ \\
\hline 28.800 & $19 / 74$ & 5837 & $\left(\begin{array}{lll}74 & 19 & 0\end{array}\right)$ & $17 \mathrm{~A}+2 \mathrm{~B}$ \\
\hline 28.841 & $9 / 35$ & 653 & 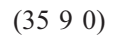 & $8 \mathrm{~A}+1 \mathrm{~B}$ \\
\hline 28.888 & $17 / 66$ & 4645 & $\left(\begin{array}{lll}66 & 17 & 0\end{array}\right)$ & $15 \mathrm{~A}+2 \mathrm{~B}$ \\
\hline 28.940 & $8 / 31$ & 1025 & $\left(\begin{array}{lll}3 & 8 & 0\end{array}\right)$ & $7 \mathrm{~A}+1 \mathrm{~B}$ \\
\hline 29.000 & $15 / 58$ & 3589 & $\left(\begin{array}{lll}58 & 15 & 0\end{array}\right)$ & $13 \mathrm{~A}+2 \mathrm{~B}$ \\
\hline 29.068 & $7 / 27$ & 389 & $\left(\begin{array}{lll}27 & 7 & 0\end{array}\right)$ & $6 \mathrm{~A}+1 \mathrm{~B}$ \\
\hline 29.148 & $13 / 50$ & 2669 & $\left(\begin{array}{lll}50 & 13 & 0\end{array}\right)$ & $11 \mathrm{~A}+2 \mathrm{~B}$ \\
\hline 29.177 & $19 / 73$ & 2845 & $\left(\begin{array}{lll}73 & 19 & 0\end{array}\right)$ & $16 A+3 B$ \\
\hline 29.241 & $6 / 23$ & 565 & $\left(\begin{array}{lll}23 & 6 & 0\end{array}\right)$ & $5 \mathrm{~A}+1 \mathrm{~B}$ \\
\hline 29.313 & $17 / 65$ & 2257 & $\left(\begin{array}{lll}65 & 17 & 0\end{array}\right)$ & $14 \mathrm{~A}+3 \mathrm{~B}$ \\
\hline 29.352 & $11 / 42$ & 1885 & $\left(\begin{array}{lll}42 & 11 & 0\end{array}\right)$ & $9 \mathrm{~A}+2 \mathrm{~B}$ \\
\hline 29.394 & $16 / 61$ & 3977 & $\left(\begin{array}{lll}61 & 16 & 0\end{array}\right)$ & $13 \mathrm{~A}+3 \mathrm{~B}$ \\
\hline 29.487 & $5 / 19$ & 193 & $\left(\begin{array}{lll}19 & 5 & 0\end{array}\right)$ & $4 \mathrm{~A}+1 \mathrm{~B}$ \\
\hline
\end{tabular}


Continued.

\begin{tabular}{|c|c|c|c|c|}
\hline $2 \theta\left[^{\circ}\right]$ & $\tan \theta$ & $\Sigma$ & g.b. plane & decomposition \\
\hline 29.565 & $19 / 72$ & 5545 & $\left(\begin{array}{lll}72 & 19 & 0\end{array}\right)$ & $15 \mathrm{~A}+4 \mathrm{~B}$ \\
\hline 29.593 & $14 / 53$ & 3005 & $\left(\begin{array}{lll}53 & 14 & 0\end{array}\right)$ & $11 \mathrm{~A}+3 \mathrm{~B}$ \\
\hline 29.652 & $9 / 34$ & 1237 & $\left(\begin{array}{lll}34 & 9 & 0\end{array}\right)$ & $7 \mathrm{~A}+2 \mathrm{~B}$ \\
\hline 29.717 & $13 / 49$ & 1285 & $\left(\begin{array}{lll}49 & 13 & 0\end{array}\right)$ & $10 A+3 B$ \\
\hline 29.751 & $17 / 64$ & 4385 & $\left(\begin{array}{lll}64 & 17 & 0\end{array}\right)$ & $13 \mathrm{~A}+4 \mathrm{~B}$ \\
\hline 29.862 & $4 / 15$ & 241 & $\left(\begin{array}{lll}15 & 4 & 0\end{array}\right)$ & $3 \mathrm{~A}+1 \mathrm{~B}$ \\
\hline 29.963 & $19 / 71$ & 2701 & $\left(\begin{array}{lll}71 & 19 & 0\end{array}\right)$ & $14 \mathrm{~A}+5 \mathrm{~B}$ \\
\hline 29.990 & $15 / 56$ & 3361 & $\left(\begin{array}{lll}56 & 15 & 0\end{array}\right)$ & $11 \mathrm{~A}+4 \mathrm{~B}$ \\
\hline 30.036 & $11 / 41$ & 901 & $\left(\begin{array}{lll}41 & 11 & 0\end{array}\right)$ & $8 \mathrm{~A}+3 \mathrm{~B}$ \\
\hline 30.075 & $18 / 67$ & 4813 & $\left(\begin{array}{lll}67 & 18 & 0\end{array}\right)$ & $13 \mathrm{~A}+5 \mathrm{~B}$ \\
\hline 30.136 & $7 / 26$ & 725 & $(2670)$ & $5 \mathrm{~A}+2 \mathrm{~B}$ \\
\hline 30.202 & $17 / 63$ & 2129 & $\left(\begin{array}{lll}63 & 17 & 0\end{array}\right)$ & $12 \mathrm{~A}+5 \mathrm{~B}$ \\
\hline 30.248 & $10 / 37$ & 1469 & $\left(\begin{array}{lll}37 & 10 & 0\end{array}\right)$ & $7 \mathrm{~A}+3 \mathrm{~B}$ \\
\hline 30.308 & $13 / 48$ & 2473 & $\left(\begin{array}{lll}48 & 13 & 0\end{array}\right)$ & $9 \mathrm{~A}+4 \mathrm{~B}$ \\
\hline 30.345 & $16 / 59$ & 3737 & $\left(\begin{array}{lll}59 & 16 & 0\end{array}\right)$ & $11 \mathrm{~A}+5 \mathrm{~B}$ \\
\hline 30.371 & $19 / 70$ & 5261 & $\left(\begin{array}{lll}70 & 19 & 0\end{array}\right)$ & $13 \mathrm{~A}+6 \mathrm{~B}$ \\
\hline 30.510 & $3 / 11$ & 65 & $\left(\begin{array}{lll}11 & 3 & 0\end{array}\right)$ & $2 \mathrm{~A}+1 \mathrm{~B}$ \\
\hline 30.666 & $17 / 62$ & 4133 & $\left(\begin{array}{lll}62 & 17 & 0\end{array}\right)$ & $11 \mathrm{~A}+6 \mathrm{~B}$ \\
\hline 30.700 & $14 / 51$ & 2797 & $\left(\begin{array}{lll}51 & 14 & 0\end{array}\right)$ & $9 \mathrm{~A}+5 \mathrm{~B}$ \\
\hline 30.752 & $11 / 40$ & 1721 & $\left(\begin{array}{lll}40 & 11 & 0\end{array}\right)$ & $7 \mathrm{~A}+4 \mathrm{~B}$ \\
\hline 30.791 & $19 / 69$ & 2561 & $\left(\begin{array}{lll}69 & 19 & 0\end{array}\right)$ & $12 \mathrm{~A}+7 \mathrm{~B}$ \\
\hline 30.844 & $8 / 29$ & 905 & $\left(\begin{array}{lll}29 & 8 & 0\end{array}\right)$ & $5 \mathrm{~A}+3 \mathrm{~B}$ \\
\hline 30.922 & $13 / 47$ & 1189 & $\left(\begin{array}{lll}47 & 13 & 0\end{array}\right)$ & $8 A+5 B$ \\
\hline 30.957 & $18 / 65$ & 4549 & $\left(\begin{array}{lll}65 & 18 & 0\end{array}\right)$ & $11 \mathrm{~A}+7 \mathrm{~B}$ \\
\hline 31.048 & $5 / 18$ & 349 & $\left(\begin{array}{lll}18 & 5 & 0\end{array}\right)$ & $3 \mathrm{~A}+2 \mathrm{~B}$ \\
\hline 31.145 & $17 / 61$ & 2005 & $\left(\begin{array}{lll}61 & 17 & 0\end{array}\right)$ & $10 A+7 B$ \\
\hline 31.185 & $12 / 43$ & 1993 & $\left(\begin{array}{lll}43 & 12 & 0\end{array}\right)$ & $7 A+5 B$ \\
\hline 31.221 & $19 / 68$ & 4985 & $\left(\begin{array}{lll}68 & 19 & 0\end{array}\right)$ & $11 \mathrm{~A}+8 \mathrm{~B}$ \\
\hline 31.284 & $7 / 25$ & 337 & $\left(\begin{array}{lll}25 & 7 & 0\end{array}\right)$ & $4 \mathrm{~A}+3 \mathrm{~B}$ \\
\hline 31.359 & $16 / 57$ & 3505 & $\left(\begin{array}{lll}57 & 16 & 0\end{array}\right)$ & $9 \mathrm{~A}+7 \mathrm{~B}$ \\
\hline 31.417 & $9 / 32$ & 1105 & $\left(\begin{array}{lll}32 & 9 & 0\end{array}\right)$ & $5 \mathrm{~A}+4 \mathrm{~B}$ \\
\hline 31.502 & $11 / 39$ & 821 & $\left(\begin{array}{lll}39 & 11 & 0\end{array}\right)$ & $6 \mathrm{~A}+5 \mathrm{~B}$ \\
\hline 31.561 & $13 / 46$ & 2285 & $\left(\begin{array}{lll}46 & 13 & 0\end{array}\right)$ & $7 A+6 B$ \\
\hline 31.605 & $15 / 53$ & 1517 & $\left(\begin{array}{lll}53 & 15 & 0\end{array}\right)$ & $8 A+7 B$ \\
\hline 31.638 & $17 / 60$ & 3889 & $\left(\begin{array}{lll}60 & 17 & 0\end{array}\right)$ & $9 \mathrm{~A}+8 \mathrm{~B}$ \\
\hline 31.664 & $19 / 67$ & 2425 & $\left(\begin{array}{lll}67 & 19 & 0\end{array}\right)$ & $10 A+9 B$ \\
\hline 31.890 & $2 / 7$ & 53 & $\left(\begin{array}{lll}7 & 2 & 0\end{array}\right)$ & $1 \mathrm{~A}+1 \mathrm{~B}$ \\
\hline 32.119 & $19 / 66$ & 4717 & $\left(\begin{array}{lll}66 & 19 & 0\end{array}\right)$ & $9 \mathrm{~A}+10 \mathrm{~B}$ \\
\hline 32.147 & $17 / 59$ & 1885 & $\left(\begin{array}{lll}59 & 17 & 0\end{array}\right)$ & $8 \mathrm{~A}+9 \mathrm{~B}$ \\
\hline 32.181 & $15 / 52$ & 2929 & $\left(\begin{array}{lll}52 & 15 & 0\end{array}\right)$ & $7 A+8 B$ \\
\hline 32.226 & $13 / 45$ & 1097 & $\left(\begin{array}{lll}45 & 13 & 0\end{array}\right)$ & $6 \mathrm{~A}+7 \mathrm{~B}$ \\
\hline 32.288 & $11 / 38$ & 1565 & $\left(\begin{array}{lll}38 & 11 & 0\end{array}\right)$ & $5 A+6 B$ \\
\hline 32.378 & $9 / 31$ & 521 & $\left(\begin{array}{lll}3 & 9 & 0\end{array}\right)$ & $4 \mathrm{~A}+5 \mathrm{~B}$ \\
\hline 32.440 & $16 / 55$ & 3281 & $\left(\begin{array}{lll}55 & 16 & 0\end{array}\right)$ & $7 A+9 B$ \\
\hline 32.520 & $7 / 24$ & 625 & $(2470)$ & $3 \mathrm{~A}+4 \mathrm{~B}$ \\
\hline 32.588 & $19 / 65$ & 2293 & $\left(\begin{array}{lll}65 & 19 & 0\end{array}\right)$ & $8 \mathrm{~A}+11 \mathrm{~B}$ \\
\hline 32.627 & $12 / 41$ & 1825 & $\left(\begin{array}{lll}41 & 12 & 0\end{array}\right)$ & $5 \mathrm{~A}+7 \mathrm{~B}$ \\
\hline 32.672 & $17 / 58$ & 3653 & $\left(\begin{array}{lll}58 & 17 & 0\end{array}\right)$ & $7 \mathrm{~A}+10 \mathrm{~B}$ \\
\hline 32.779 & $5 / 17$ & 157 & $\left(\begin{array}{lll}17 & 5 & 0\end{array}\right)$ & $2 \mathrm{~A}+3 \mathrm{~B}$ \\
\hline 32.880 & $18 / 61$ & 4045 & $\left(\begin{array}{lll}61 & 18 & 0\end{array}\right)$ & $7 \mathrm{~A}+11 \mathrm{~B}$ \\
\hline 32.920 & $13 / 44$ & 2105 & $\left(\begin{array}{lll}44 & 13 & 0\end{array}\right)$ & $5 \mathrm{~A}+8 \mathrm{~B}$ \\
\hline 33.008 & $8 / 27$ & 793 & $\left(\begin{array}{lll}27 & 8 & 0\end{array}\right)$ & $3 \mathrm{~A}+5 \mathrm{~B}$ \\
\hline 33.069 & $19 / 64$ & 4457 & $\left(\begin{array}{lll}64 & 19 & 0\end{array}\right)$ & $7 \mathrm{~A}+12 \mathrm{~B}$ \\
\hline 33.114 & $11 / 37$ & 745 & $\left(\begin{array}{lll}37 & 11 & 0\end{array}\right)$ & $4 \mathrm{~A}+7 \mathrm{~B}$ \\
\hline 33.174 & $14 / 47$ & 2405 & $\left(\begin{array}{lll}47 & 14 & 0\end{array}\right)$ & $5 \mathrm{~A}+9 \mathrm{~B}$ \\
\hline 33.213 & $17 / 57$ & 1769 & $\left(\begin{array}{lll}57 & 17 & 0\end{array}\right)$ & $6 \mathrm{~A}+11 \mathrm{~B}$ \\
\hline
\end{tabular}

Continued.

\begin{tabular}{|c|c|c|c|c|}
\hline $2 \theta\left[^{\circ}\right]$ & $\tan \theta$ & $\Sigma$ & g.b. plane & decomposition \\
\hline 33.398 & $3 / 10$ & 109 & $\left(\begin{array}{lll}10 & 3 & 0\end{array}\right)$ & $1 \mathrm{~A}+2 \mathrm{~B}$ \\
\hline 33.565 & $19 / 63$ & 2165 & $\left(\begin{array}{lll}63 & 19 & 0\end{array}\right)$ & $6 \mathrm{~A}+13 \mathrm{~B}$ \\
\hline 33.596 & $16 / 53$ & 3065 & $\left(\begin{array}{lll}53 & 16 & 0\end{array}\right)$ & $5 \mathrm{~A}+11 \mathrm{~B}$ \\
\hline 33.642 & $13 / 43$ & 1009 & $\left(\begin{array}{lll}43 & 13 & 0\end{array}\right)$ & $4 \mathrm{~A}+9 \mathrm{~B}$ \\
\hline 33.716 & $10 / 33$ & 1189 & $\left(\begin{array}{lll}33 & 10 & 0\end{array}\right)$ & $3 \mathrm{~A}+7 \mathrm{~B}$ \\
\hline 33.773 & $17 / 56$ & 3425 & $\left(\begin{array}{lll}56 & 17 & 0\end{array}\right)$ & $5 \mathrm{~A}+12 \mathrm{~B}$ \\
\hline 33.855 & $7 / 23$ & 289 & $(2370)$ & $2 \mathrm{~A}+5 \mathrm{~B}$ \\
\hline 33.932 & $18 / 59$ & 3805 & $\left(\begin{array}{lll}59 & 18 & 0\end{array}\right)$ & $5 \mathrm{~A}+13 \mathrm{~B}$ \\
\hline 33.981 & $11 / 36$ & 1417 & $\left(\begin{array}{lll}36 & 11 & 0\end{array}\right)$ & $3 \mathrm{~A}+8 \mathrm{~B}$ \\
\hline 34.041 & $15 / 49$ & 1313 & $\left(\begin{array}{lll}49 & 15 & 0\end{array}\right)$ & $4 \mathrm{~A}+11 \mathrm{~B}$ \\
\hline 34.075 & $19 / 62$ & 4205 & $\left(\begin{array}{lll}62 & 19 & 0\end{array}\right)$ & $5 \mathrm{~A}+14 \mathrm{~B}$ \\
\hline 34.205 & $4 / 13$ & 185 & $\left(\begin{array}{lll}13 & 4 & 0\end{array}\right)$ & $1 \mathrm{~A}+3 \mathrm{~B}$ \\
\hline 34.351 & $17 / 55$ & 1657 & $\left(\begin{array}{lll}55 & 17 & 0\end{array}\right)$ & $4 \mathrm{~A}+13 \mathrm{~B}$ \\
\hline 34.397 & $13 / 42$ & 1933 & $\left(\begin{array}{lll}42 & 13 & 0\end{array}\right)$ & $3 \mathrm{~A}+10 \mathrm{~B}$ \\
\hline 34.482 & $9 / 29$ & 461 & $(2990)$ & $2 \mathrm{~A}+7 \mathrm{~B}$ \\
\hline 34.562 & $14 / 45$ & 2221 & $\left(\begin{array}{lll}45 & 14 & 0\end{array}\right)$ & $3 \mathrm{~A}+11 \mathrm{~B}$ \\
\hline 34.601 & $19 / 61$ & 2041 & $\left(\begin{array}{lll}61 & 19 & 0\end{array}\right)$ & $4 \mathrm{~A}+15 \mathrm{~B}$ \\
\hline 34.708 & $5 / 16$ & 281 & $\left(\begin{array}{lll}16 & 5 & 0\end{array}\right)$ & $1 \mathrm{~A}+4 \mathrm{~B}$ \\
\hline 34.835 & $16 / 51$ & 2857 & $\left(\begin{array}{lll}51 & 16 & 0\end{array}\right)$ & $3 \mathrm{~A}+13 \mathrm{~B}$ \\
\hline 34.894 & $11 / 35$ & 673 & $\left(\begin{array}{lll}35 & 11 & 0\end{array}\right)$ & $2 \mathrm{~A}+9 \mathrm{~B}$ \\
\hline 34.949 & $17 / 54$ & 3205 & $\left(\begin{array}{lll}54 & 17 & 0\end{array}\right)$ & $3 \mathrm{~A}+14 \mathrm{~B}$ \\
\hline 35.051 & $6 / 19$ & 397 & $\left(\begin{array}{lll}19 & 6 & 0\end{array}\right)$ & $1 \mathrm{~A}+5 \mathrm{~B}$ \\
\hline 35.142 & $19 / 60$ & 3961 & $\left(\begin{array}{lll}60 & 19 & 0\end{array}\right)$ & $3 \mathrm{~A}+16 \mathrm{~B}$ \\
\hline 35.184 & $13 / 41$ & 925 & $\left(\begin{array}{lll}41 & 13 & 0\end{array}\right)$ & $2 \mathrm{~A}+11 \mathrm{~B}$ \\
\hline 35.300 & $7 / 22$ & 533 & $(2270)$ & $1 \mathrm{~A}+6 \mathrm{~B}$ \\
\hline 35.400 & $15 / 47$ & 1217 & $\left(\begin{array}{lll}47 & 15 & 0\end{array}\right)$ & $2 \mathrm{~A}+13 \mathrm{~B}$ \\
\hline 35.489 & $8 / 25$ & 689 & $\left(\begin{array}{lll}25 & 8 & 0\end{array}\right)$ & $1 \mathrm{~A}+7 \mathrm{~B}$ \\
\hline 35.567 & $17 / 53$ & 1549 & $\left(\begin{array}{lll}53 & 17 & 0\end{array}\right)$ & $2 \mathrm{~A}+15 \mathrm{~B}$ \\
\hline 35.637 & $9 / 28$ & 865 & $\left(\begin{array}{lll}28 & 9 & 0\end{array}\right)$ & $1 \mathrm{~A}+8 \mathrm{~B}$ \\
\hline 35.700 & $19 / 59$ & 1921 & $\left(\begin{array}{lll}59 & 19 & 0\end{array}\right)$ & $2 \mathrm{~A}+17 \mathrm{~B}$ \\
\hline 35.757 & $10 / 31$ & 1061 & $\left(\begin{array}{lll}31 & 10 & 0\end{array}\right)$ & $1 \mathrm{~A}+9 \mathrm{~B}$ \\
\hline 35.855 & $11 / 34$ & 1277 & $\left(\begin{array}{lll}34 & 11 & 0\end{array}\right)$ & $1 \mathrm{~A}+10 \mathrm{~B}$ \\
\hline 35.938 & $12 / 37$ & 1513 & $\left(\begin{array}{lll}37 & 12 & 0\end{array}\right)$ & $1 \mathrm{~A}+11 \mathrm{~B}$ \\
\hline 36.008 & $13 / 40$ & 1769 & $\left(\begin{array}{lll}40 & 13 & 0\end{array}\right)$ & $1 \mathrm{~A}+12 \mathrm{~B}$ \\
\hline 36.068 & $14 / 43$ & 2045 & $\left(\begin{array}{lll}43 & 14 & 0\end{array}\right)$ & $1 \mathrm{~A}+13 \mathrm{~B}$ \\
\hline 36.120 & $15 / 46$ & 2341 & $\left(\begin{array}{lll}46 & 15 & 0\end{array}\right)$ & $1 \mathrm{~A}+14 \mathrm{~B}$ \\
\hline 36.166 & $16 / 49$ & 2657 & $\left(\begin{array}{lll}49 & 16 & 0\end{array}\right)$ & $1 \mathrm{~A}+15 \mathrm{~B}$ \\
\hline 36.207 & $17 / 52$ & 2993 & $\left(\begin{array}{lll}52 & 17 & 0\end{array}\right)$ & $1 \mathrm{~A}+16 \mathrm{~B}$ \\
\hline 36.243 & $18 / 55$ & 3349 & $\left(\begin{array}{lll}55 & 18 & 0\end{array}\right)$ & $1 \mathrm{~A}+17 \mathrm{~B}$ \\
\hline 36.276 & $19 / 58$ & 3725 & $\left(\begin{array}{lll}58 & 19 & 0\end{array}\right)$ & $1 \mathrm{~A}+18 \mathrm{~B}$ \\
\hline 36.869 & $1 / 3$ & 5 & $\left(\begin{array}{lll}3 & 1 & 0\end{array}\right)$ & B \\
\hline 37.482 & $19 / 56$ & 3497 & $\left(\begin{array}{lll}56 & 19 & 0\end{array}\right)$ & $18 B+1 C$ \\
\hline 37.517 & $18 / 53$ & 3133 & $\left(\begin{array}{lll}53 & 18 & 0\end{array}\right)$ & $17 B+1 C$ \\
\hline 37.556 & $17 / 50$ & 2789 & $\left(\begin{array}{lll}50 & 17 & 0\end{array}\right)$ & $16 B+1 C$ \\
\hline 37.599 & $16 / 47$ & 2465 & $\left(\begin{array}{lll}47 & 16 & 0\end{array}\right)$ & $15 B+1 C$ \\
\hline 37.649 & $15 / 44$ & 2161 & $\left(\begin{array}{lll}44 & 15 & 0\end{array}\right)$ & $14 B+1 C$ \\
\hline 37.706 & $14 / 41$ & 1877 & $\left(\begin{array}{lll}41 & 14 & 0\end{array}\right)$ & $13 B+1 C$ \\
\hline 37.772 & $13 / 38$ & 1613 & $\left(\begin{array}{lll}38 & 13 & 0\end{array}\right)$ & $12 B+1 C$ \\
\hline 37.849 & $12 / 35$ & 1369 & $\left(\begin{array}{lll}35 & 12 & 0\end{array}\right)$ & $11 B+1 C$ \\
\hline 37.940 & $11 / 32$ & 1145 & $\left(\begin{array}{lll}32 & 11 & 0\end{array}\right)$ & $10 \mathrm{~B}+1 \mathrm{C}$ \\
\hline 38.051 & $10 / 29$ & 941 & $\left(\begin{array}{lll}29 & 10 & 0\end{array}\right)$ & $9 B+1 C$ \\
\hline 38.115 & $19 / 55$ & 1693 & $\left(\begin{array}{lll}55 & 19 & 0\end{array}\right)$ & $17 B+2 C$ \\
\hline 38.186 & $9 / 26$ & 757 & $\left(\begin{array}{lll}26 & 9 & 0\end{array}\right)$ & $8 B+1 C$ \\
\hline 38.267 & $17 / 49$ & 1345 & $\left(\begin{array}{lll}49 & 17 & 0\end{array}\right)$ & $15 B+2 C$ \\
\hline 38.358 & $8 / 23$ & 593 & $\left(\begin{array}{lll}23 & 8 & 0\end{array}\right)$ & $7 \mathrm{~B}+1 \mathrm{C}$ \\
\hline 38.461 & $15 / 43$ & 1037 & $\left(\begin{array}{lll}43 & 15 & 0\end{array}\right)$ & $13 B+2 C$ \\
\hline
\end{tabular}

Continued on next page. 
Continued.

\begin{tabular}{|c|c|c|c|c|}
\hline $2 \theta\left[^{\circ}\right]$ & $\tan \theta$ & $\Sigma$ & g.b. plane & decomposition \\
\hline 38.580 & $7 / 20$ & 449 & 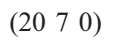 & $6 B+1 C$ \\
\hline 38.717 & $13 / 37$ & 769 & $\left(\begin{array}{lll}37 & 13 & 0\end{array}\right)$ & $11 B+2 C$ \\
\hline 38.769 & $19 / 54$ & 3277 & $\left(\begin{array}{lll}54 & 19 & 0\end{array}\right)$ & $16 B+3 C$ \\
\hline 38.880 & $6 / 17$ & 325 & $\left(\begin{array}{lll}17 & 6 & 0\end{array}\right)$ & $5 B+1 C$ \\
\hline 39.004 & $17 / 48$ & 2593 & $\left(\begin{array}{lll}48 & 17 & 0\end{array}\right)$ & $14 B+3 C$ \\
\hline 39.073 & $11 / 31$ & 541 & 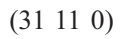 & $9 B+2 C$ \\
\hline 39.146 & $16 / 45$ & 2281 & $\left(\begin{array}{lll}45 & 16 & 0\end{array}\right)$ & $13 B+3 C$ \\
\hline 39.307 & $5 / 14$ & 221 & $\left(\begin{array}{lll}14 & 5 & 0\end{array}\right)$ & $4 B+1 C$ \\
\hline 39.444 & $19 / 53$ & 1585 & $\left(\begin{array}{lll}53 & 19 & 0\end{array}\right)$ & $15 B+4 C$ \\
\hline 39.493 & $14 / 39$ & 1717 & $\left(\begin{array}{lll}39 & 14 & 0\end{array}\right)$ & $11 B+3 C$ \\
\hline 39.597 & $9 / 25$ & 353 & $\left(\begin{array}{lll}25 & 9 & 0\end{array}\right)$ & $7 B+2 C$ \\
\hline 39.710 & $13 / 36$ & 1465 & $\left(\begin{array}{lll}36 & 13 & 0\end{array}\right)$ & $10 B+3 C$ \\
\hline 39.770 & $17 / 47$ & 1249 & $\left(\begin{array}{lll}47 & 17 & 0\end{array}\right)$ & $13 B+4 C$ \\
\hline 39.966 & $4 / 11$ & 137 & $\left(\begin{array}{lll}11 & 4 & 0\end{array}\right)$ & $3 B+1 C$ \\
\hline 40.143 & $19 / 52$ & 3065 & $\left(\begin{array}{lll}52 & 19 & 0\end{array}\right)$ & $14 B+5 C$ \\
\hline 40.190 & $15 / 41$ & 953 & $\left(\begin{array}{lll}41 & 15 & 0\end{array}\right)$ & $11 B+4 C$ \\
\hline 40.272 & $11 / 30$ & 1021 & $\left(\begin{array}{lll}30 & 11 & 0\end{array}\right)$ & $8 B+3 C$ \\
\hline 40.341 & $18 / 49$ & 2725 & $\left(\begin{array}{lll}49 & 18 & 0\end{array}\right)$ & $13 B+5 C$ \\
\hline 40.449 & $7 / 19$ & 205 & $\left(\begin{array}{lll}19 & 7 & 0\end{array}\right)$ & $5 B+2 C$ \\
\hline 40.565 & $17 / 46$ & 2405 & $\left(\begin{array}{lll}46 & 17 & 0\end{array}\right)$ & $12 B+5 C$ \\
\hline 40.646 & $10 / 27$ & 829 & $\left(\begin{array}{lll}27 & 10 & 0\end{array}\right)$ & $7 B+3 C$ \\
\hline 40.752 & $13 / 35$ & 697 & $\left(\begin{array}{lll}35 & 13 & 0\end{array}\right)$ & $9 B+4 C$ \\
\hline 40.819 & $16 / 43$ & 2105 & $\left(\begin{array}{lll}43 & 16 & 0\end{array}\right)$ & $11 B+5 C$ \\
\hline 40.865 & $19 / 51$ & 1481 & $\left(\begin{array}{lll}51 & 19 & 0\end{array}\right)$ & $13 B+6 C$ \\
\hline 41.112 & $3 / 8$ & 73 & $\left(\begin{array}{lll}8 & 3 & 0\end{array}\right)$ & $2 B+1 C$ \\
\hline 41.390 & $17 / 45$ & 1157 & $\left(\begin{array}{lll}45 & 17 & 0\end{array}\right)$ & $11 B+6 C$ \\
\hline 41.451 & $14 / 37$ & 1565 & $\left(\begin{array}{lll}37 & 14 & 0\end{array}\right)$ & $9 B+5 C$ \\
\hline 41.544 & $11 / 29$ & 481 & $\left(\begin{array}{lll}29 & 11 & 0\end{array}\right)$ & $7 B+4 C$ \\
\hline 41.613 & $19 / 50$ & 2861 & $\left(\begin{array}{lll}50 & 19 & 0\end{array}\right)$ & $12 B+7 C$ \\
\hline 41.708 & $8 / 21$ & 505 & 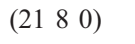 & $5 B+3 C$ \\
\hline 41.849 & $13 / 34$ & 1325 & $\left(\begin{array}{lll}34 & 13 & 0\end{array}\right)$ & $8 B+5 C$ \\
\hline 41.911 & $18 / 47$ & 2533 & $\left(\begin{array}{lll}47 & 18 & 0\end{array}\right)$ & $11 \mathrm{~B}+7 \mathrm{C}$ \\
\hline 42.075 & $5 / 13$ & 97 & $\left(\begin{array}{lll}13 & 5 & 0\end{array}\right)$ & $3 B+2 C$ \\
\hline 42.249 & $17 / 44$ & 2225 & $\left(\begin{array}{lll}44 & 17 & 0\end{array}\right)$ & $10 B+7 C$ \\
\hline 42.322 & $12 / 31$ & 1105 & $\left(\begin{array}{lll}3 & 12 & 0\end{array}\right)$ & $7 B+5 C$ \\
\hline 42.388 & $19 / 49$ & 1381 & $\left(\begin{array}{lll}49 & 19 & 0\end{array}\right)$ & $11 B+8 C$ \\
\hline 42.501 & $7 / 18$ & 373 & $\left(\begin{array}{lll}18 & 7 & 0\end{array}\right)$ & $4 B+3 C$ \\
\hline 42.635 & $16 / 41$ & 1937 & $\left(\begin{array}{lll}41 & 16 & 0\end{array}\right)$ & $9 B+7 C$ \\
\hline 42.741 & $9 / 23$ & 305 & $\left(\begin{array}{lll}23 & 9 & 0\end{array}\right)$ & $5 B+4 C$ \\
\hline 42.895 & $11 / 28$ & 905 & $\left(\begin{array}{lll}28 & 11 & 0\end{array}\right)$ & $6 B+5 C$ \\
\hline 43.002 & $13 / 33$ & 629 & $\left(\begin{array}{lll}33 & 13 & 0\end{array}\right)$ & $7 B+6 C$ \\
\hline 43.081 & $15 / 38$ & 1669 & $\left(\begin{array}{lll}38 & 15 & 0\end{array}\right)$ & $8 B+7 C$ \\
\hline 43.142 & $17 / 43$ & 1069 & $\left(\begin{array}{lll}43 & 17 & 0\end{array}\right)$ & $9 \mathrm{~B}+8 \mathrm{C}$ \\
\hline 43.190 & $19 / 48$ & 2665 & $\left(\begin{array}{lll}48 & 19 & 0\end{array}\right)$ & $10 B+9 C$ \\
\hline 43.602 & $2 / 5$ & 29 & $\left(\begin{array}{lll}5 & 2 & 0\end{array}\right)$ & $1 \mathrm{~B}+1 \mathrm{C}$ \\
\hline 44.022 & $19 / 47$ & 1285 & $\left(\begin{array}{lll}47 & 19 & 0\end{array}\right)$ & $9 B+10 C$ \\
\hline 44.072 & $17 / 42$ & 2053 & $\left(\begin{array}{lll}42 & 17 & 0\end{array}\right)$ & $8 B+9 C$ \\
\hline 44.135 & $15 / 37$ & 797 & $\left(\begin{array}{lll}37 & 15 & 0\end{array}\right)$ & $7 B+8 C$ \\
\hline 44.218 & $13 / 32$ & 1193 & $\left(\begin{array}{lll}32 & 13 & 0\end{array}\right)$ & $6 B+7 C$ \\
\hline 44.332 & $11 / 27$ & 425 & $\left(\begin{array}{lll}27 & 11 & 0\end{array}\right)$ & $5 B+6 C$ \\
\hline 44.498 & $9 / 22$ & 565 & $\left(\begin{array}{lll}22 & 9 & 0\end{array}\right)$ & $4 B+5 C$ \\
\hline 44.612 & $16 / 39$ & 1777 & $\left(\begin{array}{lll}39 & 16 & 0\end{array}\right)$ & $7 B+9 C$ \\
\hline 44.760 & $7 / 17$ & 169 & $\left(\begin{array}{lll}17 & 7 & 0\end{array}\right)$ & $3 B+4 C$ \\
\hline 44.885 & $19 / 46$ & 2477 & $\left(\begin{array}{lll}46 & 19 & 0\end{array}\right)$ & $8 B+11 C$ \\
\hline 44.958 & $12 / 29$ & 985 & $\left(\begin{array}{lll}29 & 12 & 0\end{array}\right)$ & $5 B+7 C$ \\
\hline 45.041 & $17 / 41$ & 985 & $\left(\begin{array}{lll}41 & 17 & 0\end{array}\right)$ & $7 B+10 C$ \\
\hline
\end{tabular}

Continued.

\begin{tabular}{|c|c|c|c|c|}
\hline $2 \theta\left[^{\circ}\right]$ & $\tan \theta$ & $\Sigma$ & g.b. plane & decomposition \\
\hline 45.239 & $5 / 12$ & 169 & $\left(\begin{array}{lll}12 & 5 & 0\end{array}\right)$ & $2 B+3 C$ \\
\hline 45.428 & $18 / 43$ & 2173 & $\left(\begin{array}{lll}43 & 18 & 0\end{array}\right)$ & $7 B+11 C$ \\
\hline 45.501 & $13 / 31$ & 565 & $\left(\begin{array}{lll}31 & 13 & 0\end{array}\right)$ & $5 B+8 C$ \\
\hline 45.667 & $8 / 19$ & 425 & $\left(\begin{array}{lll}19 & 8 & 0\end{array}\right)$ & $3 B+5 C$ \\
\hline 45.781 & $19 / 45$ & 1193 & $\left(\begin{array}{lll}45 & 19 & 0\end{array}\right)$ & $7 B+12 C$ \\
\hline 45.864 & $11 / 26$ & 797 & $\left(\begin{array}{lll}26 & 11 & 0\end{array}\right)$ & $4 B+7 C$ \\
\hline 45.977 & $14 / 33$ & 1285 & $\left(\begin{array}{lll}33 & 14 & 0\end{array}\right)$ & $5 B+9 C$ \\
\hline 46.050 & $17 / 40$ & 1889 & $\left(\begin{array}{lll}40 & 17 & 0\end{array}\right)$ & $6 \mathrm{~B}+11 \mathrm{C}$ \\
\hline 46.397 & $3 / 7$ & 29 & $\left(\begin{array}{lll}7 & 3 & 0\end{array}\right)$ & $1 \mathrm{~B}+2 \mathrm{C}$ \\
\hline 46.711 & $19 / 44$ & 2297 & $\left(\begin{array}{lll}44 & 19 & 0\end{array}\right)$ & $6 B+13 C$ \\
\hline 46.770 & $16 / 37$ & 1625 & $\left(\begin{array}{lll}37 & 16 & 0\end{array}\right)$ & $5 B+11 C$ \\
\hline 46.857 & $13 / 30$ & 1069 & $\left(\begin{array}{lll}30 & 13 & 0\end{array}\right)$ & $4 B+9 C$ \\
\hline 46.997 & $10 / 23$ & 629 & $\left(\begin{array}{lll}23 & 10 & 0\end{array}\right)$ & $3 B+7 C$ \\
\hline 47.104 & $17 / 39$ & 905 & $\left(\begin{array}{lll}39 & 17 & 0\end{array}\right)$ & $5 B+12 C$ \\
\hline 47.258 & $7 / 16$ & 305 & $\left(\begin{array}{lll}16 & 7 & 0\end{array}\right)$ & $2 \mathrm{~B}+5 \mathrm{C}$ \\
\hline 47.405 & $18 / 41$ & 2005 & $\left(\begin{array}{lll}41 & 18 & 0\end{array}\right)$ & $5 B+13 C$ \\
\hline 47.498 & $11 / 25$ & 373 & $\left(\begin{array}{lll}25 & 11 & 0\end{array}\right)$ & $3 B+8 C$ \\
\hline 47.611 & $15 / 34$ & 1381 & $\left(\begin{array}{lll}34 & 15 & 0\end{array}\right)$ & $4 B+11 C$ \\
\hline 47.677 & $19 / 43$ & 1105 & $\left(\begin{array}{lll}43 & 19 & 0\end{array}\right)$ & $5 B+14 C$ \\
\hline 47.924 & $4 / 9$ & 97 & $\left(\begin{array}{lll}9 & 4 & 0\end{array}\right)$ & $1 B+3 C$ \\
\hline 48.204 & $17 / 38$ & 1733 & $\left(\begin{array}{lll}38 & 17 & 0\end{array}\right)$ & $4 B+13 C$ \\
\hline 48.291 & $13 / 29$ & 505 & $\left(\begin{array}{lll}29 & 13 & 0\end{array}\right)$ & $3 B+10 C$ \\
\hline 48.455 & $9 / 20$ & 481 & $(2090)$ & $2 B+7 C$ \\
\hline 48.609 & $14 / 31$ & 1157 & $\left(\begin{array}{lll}31 & 14 & 0\end{array}\right)$ & $3 B+11 C$ \\
\hline 48.682 & $19 / 42$ & 2125 & $\left(\begin{array}{lll}42 & 19 & 0\end{array}\right)$ & $4 B+15 C$ \\
\hline 48.887 & $5 / 11$ & 73 & $\left(\begin{array}{lll}1 & 5 & 0\end{array}\right)$ & $1 B+4 C$ \\
\hline 49.134 & $16 / 35$ & 1481 & $\left(\begin{array}{lll}35 & 16 & 0\end{array}\right)$ & $3 B+13 C$ \\
\hline 49.247 & $11 / 24$ & 697 & $\left(\begin{array}{lll}24 & 11 & 0\end{array}\right)$ & $2 B+9 C$ \\
\hline 49.353 & $17 / 37$ & 829 & $\left(\begin{array}{lll}37 & 17 & 0\end{array}\right)$ & $3 B+14 C$ \\
\hline 49.550 & $6 / 13$ & 205 & $\left(\begin{array}{lll}13 & 6 & 0\end{array}\right)$ & $1 \mathrm{~B}+5 \mathrm{C}$ \\
\hline 49.727 & $19 / 41$ & 1021 & $\left(\begin{array}{lll}41 & 19 & 0\end{array}\right)$ & $3 B+16 C$ \\
\hline 49.809 & $13 / 28$ & 953 & $\left(\begin{array}{lll}28 & 13 & 0\end{array}\right)$ & $2 B+11 C$ \\
\hline 50.033 & $7 / 15$ & 137 & $\left(\begin{array}{lll}15 & 7 & 0\end{array}\right)$ & $1 B+6 C$ \\
\hline 50.229 & $15 / 32$ & 1249 & $\left(\begin{array}{lll}32 & 15 & 0\end{array}\right)$ & $2 B+13 C$ \\
\hline 50.402 & $8 / 17$ & 353 & $\left(\begin{array}{lll}17 & 8 & 0\end{array}\right)$ & $1 B+7 C$ \\
\hline 50.555 & $17 / 36$ & 1585 & $\left(\begin{array}{lll}36 & 17 & 0\end{array}\right)$ & $2 \mathrm{~B}+15 \mathrm{C}$ \\
\hline 50.692 & $9 / 19$ & 221 & $\left(\begin{array}{lll}19 & 9 & 0\end{array}\right)$ & $1 \mathrm{~B}+8 \mathrm{C}$ \\
\hline 50.815 & $19 / 40$ & 1961 & $\left(\begin{array}{lll}40 & 19 & 0\end{array}\right)$ & $2 B+17 C$ \\
\hline 50.926 & $10 / 21$ & 541 & $\left(\begin{array}{lll}21 & 10 & 0\end{array}\right)$ & $1 B+9 \mathrm{C}$ \\
\hline 51.119 & $11 / 23$ & 325 & $\left(\begin{array}{lll}23 & 11 & 0\end{array}\right)$ & $1 \mathrm{~B}+10 \mathrm{C}$ \\
\hline 51.282 & $12 / 25$ & 769 & $\left(\begin{array}{lll}25 & 12 & 0\end{array}\right)$ & $1 B+11 C$ \\
\hline 51.419 & $13 / 27$ & 449 & $\left(\begin{array}{lll}27 & 13 & 0\end{array}\right)$ & $1 B+12 C$ \\
\hline 51.538 & $14 / 29$ & 1037 & $\left(\begin{array}{lll}29 & 14 & 0\end{array}\right)$ & $1 B+13 C$ \\
\hline 51.641 & $15 / 31$ & 593 & $\left(\begin{array}{lll}31 & 15 & 0\end{array}\right)$ & $1 B+14 C$ \\
\hline 51.732 & $16 / 33$ & 1345 & $\left(\begin{array}{lll}33 & 16 & 0\end{array}\right)$ & $1 B+15 C$ \\
\hline 51.813 & $17 / 35$ & 757 & $\left(\begin{array}{lll}35 & 17 & 0\end{array}\right)$ & $1 B+16 C$ \\
\hline 51.884 & $18 / 37$ & 1693 & $\left(\begin{array}{lll}37 & 18 & 0\end{array}\right)$ & $1 B+17 C$ \\
\hline 51.948 & $19 / 39$ & 941 & $\left(\begin{array}{lll}39 & 19 & 0\end{array}\right)$ & $1 \mathrm{~B}+18 \mathrm{C}$ \\
\hline 53.130 & $1 / 2$ & 5 & $\left(\begin{array}{lll}2 & 1 & 0\end{array}\right)$ & C \\
\hline
\end{tabular}

